\title{
Electrical, thermal and infrared studies of cadmium metavanadate
}

\author{
N SURESH RAO and O G PALANNA* \\ Department of Chemistry, St Philomena College, Puttur 574202 , India \\ MS received 2 April 1996; revised 30 August 1996
}

\begin{abstract}
Cadmium(II) metavanadate has crystal structure related to brannerite $\left(\mathrm{ThTi}_{2} \mathrm{O}_{6}\right)$ structure. The high temperature $\beta-\mathrm{CdV}_{2} \mathrm{O}_{6}$ phase is $n$-type semiconductor between 185 and $750 \mathrm{C}$. The electrical conduction in the $\beta-\mathrm{CdV}_{2} \mathrm{O}_{6}$ occurs due to deviation from oxygen stoichiometric composition of the lattice. The seebeck coefficient $(\alpha)$ of the sample is negative and constant in the entire range of investigation. The mechanism of transport in cadmium metavanadate lattice is via thermally activated hopping of localized electrons on vanadium $\left(\mathrm{V}^{5+}\right)$ sites of the lattice. The DTA result indicated that $\mathrm{CdV}_{2} \mathrm{O}_{6}$ undergoes phase transition at $185^{\circ} \mathrm{C}$ and not at $670^{\circ} \mathrm{C}$ as reported earlier. There is no DTA evidence to show the possibility of $\beta \rightarrow \alpha$ phase reverse transition. The XRD powder patterns of the two modifications are nearly similar indicating brannerite related structures. The infrared absorption band of vanadiumoxygen stretching vibration modes of distorted $\mathrm{VO}_{6}$ octahedra of $\beta-\mathrm{CdV}_{2} \mathrm{O}_{6}$ is exhibited at $855 \mathrm{~cm}^{-1}$.
\end{abstract}

Keywords. Crystal structure; semiconductor; stoichiometric; phase transition.

\section{Introduction}

Cadmium metavanadate $\left(\mathrm{CdV}_{2} \mathrm{O}_{6}\right)$ was identified in the phase studies of binary oxides of CdO- $\mathrm{V}_{2} \mathrm{O}_{5}$ (Tammann and Kelsing 1925; Angenault 1967, 1970; Bouloux and Galy 1969; Bouloux et al 1972; Brown 1972). Tammann and Kelsing (1925) and Brown (1972) noticed an eutectic temperature at $650 \pm 15^{\circ} \mathrm{C}$ during the phase studies of $\mathrm{CdO}-\mathrm{V}_{2} \mathrm{O}_{5}$. Bouloux and Galy (1969) obtained $\alpha-\mathrm{CdV}_{2} \mathrm{O}_{6}$ by heating equimolar amounts of $\mathrm{CdO}$ and $\mathrm{V}_{2} \mathrm{O}_{5}$ at $580^{\circ} \mathrm{C}$ for $24 \mathrm{~h}$ and also prepared $\beta-\mathrm{CdV}_{2} \mathrm{O}_{6}$ by either heating $\alpha-\mathrm{CdV}_{2} \mathrm{O}_{6}$ for $5-6 \mathrm{~h}$ at $750^{\circ} \mathrm{C}$ or by fusing $\alpha-\mathrm{CdV}_{2} \mathrm{O}_{6}$ to molten state and quenching to room temperature. Both modifications of $\mathrm{CdV}_{2} \mathrm{O}_{6}$ crystallized in the brannerite related crystal structures (Wadsley and Ruh 1966). $\alpha-\mathrm{CdV}_{2} \mathrm{O}_{6}$ phase is yellow and changes to brown after phase transition with volume contraction $(10 \%)$ of the unit cell from $243 \AA^{3}$ to $216 \AA^{3}$. The crystal structure of $\alpha-\mathrm{CdV}_{2} \mathrm{O}_{6}$ is monoclinic (space group: $C 2 / m$ ) (Bouloux et al 1972), while that of $\beta-\mathrm{CdV}_{2} \mathrm{O}_{6}$ is also monoclinic $(C 2 / m)$ (Bouloux and Galy 1969) isostructural with brannerite crystal structure [monoclinic, $C 2 / m$ ]. Angenault (1970) did not observe phase transition and could synthesize only $\beta-\mathrm{CdV}_{2} \mathrm{O}_{6}$. Brown (1972) prepared a yellow coloured $\mathrm{CdV}_{2} \mathrm{O}_{6}$ which transformed to high temperature $\beta-\mathrm{CdV}_{2} \mathrm{O}_{6}$ phase at $180 \pm 10^{\circ} \mathrm{C}$ with a distinct colour change (brown). The phase transition observed for $\mathrm{CdV}_{2} \mathrm{O}_{6}$ is reversible. The $\mathrm{CdV}_{2} \mathrm{O}_{6}$ phase melts congruently at $800^{\circ} \mathrm{C}$. Apart from these, no other information is available in literature.

Vanadates of cations (trivalent/divalent) have extensive industrial applications as phosphors/luminescent materials. As a part of the investigation of $\mathrm{MO}-\mathrm{V}_{2} \mathrm{O}_{5}$ systems (where $\mathrm{M}=$ cation), we are prompted to investigate the electrical, thermal and infrared studies of $\mathrm{CdV}_{2} \mathrm{O}_{6}$ phase. The results are discussed in the present paper.

*Author for correspondence 


\section{Experimental}

Cadmium(II) vanadate was obtained by heating an equimolar ratio $(1: 1)$ of $\mathrm{CdCO}_{3}$ and $\mathrm{V}_{2} \mathrm{O}_{5}$ (both Mathey-Johnson/Baker AR Grade) at $500^{\circ} \mathrm{C}$ for $36 \mathrm{~h}$ adopting conventional solid state ceramic technique. The dc electrical conductivity $(\sigma)$ of the sample was obtained by measuring the resistance of the sample by current-voltage method using $12 \mathrm{~V}$ dc source and standard resistances. The seebeck coefficient $(\alpha$, $\mu \mathrm{v} /$ degree) was measured by integral method between 185 and $750^{\circ} \mathrm{C}$. The sample ( $18 \mathrm{~mm}$ dia., $2 \mathrm{~mm}$ thickness) was in the form of sintered pellet of about $85 \%$ density. The differential thermal analysis (DTA) of the sample was carried out in the laboratory built unit and was recorded using a sensitive strip chart recorder (ECIL India Pvt. Ltd). The following conditions were maintained during DTA run of the sample: (i) the sample holder, Pt cups, (ii) reference material, ignited anhydrous $\mathrm{Al}_{2} \mathrm{O}_{3}$, (iii) heating rate, $8^{\circ} / \mathrm{min}$, and (iv) atmosphere, static air. The XRD powder patterns of the sample were obtained on a Philips X-ray diffractometer (Ni filter, $\lambda=1.5418 \AA$ ) using $\mathrm{CuK}_{\alpha}$ radiation. The infrared spectrum of $\mathrm{CdV}_{2} \mathrm{O}_{6}$ was recorded in nujol mull on a PerkinElmer spectrophotometer.

\section{Results and discussion}

The XRD powder patterns of the samples prepared under different conditions agrees with both $\alpha$ and $\beta$ phases of $\mathrm{CdV}_{2} \mathrm{O}_{6}$ (Bouloux and Galy 1969; Bouloux et al 1972; Brown 1972; ASTM card file NO 20-189). These phases are isotypic with brannerite (Wadsley and Ruh 1966) related crystal structures such as $\mathrm{MgV}_{2} \mathrm{O}_{6}(\mathrm{Ng}$ and Calvo 1972; Palanna 1979), $\mathrm{ZnV}_{2} \mathrm{O}_{6}$ (Angenault 1970) and $\mathrm{CuV}_{2} \mathrm{O}_{6}$ (Lavaud and Galy 1972). Bouloux et al (1972) reported that low temperature $\alpha-\mathrm{CdV}_{2} \mathrm{O}_{6}$ phase is isostructural with $\mathrm{CaV}_{2} \mathrm{O}_{6}$ (both monoclinic, $\mathrm{C} 2 / \mathrm{m}$ ) and observed similar XRD patterns. In the present investigation, XRD results of the samples of annealed (heated to $600^{\circ} \mathrm{C}$ for $4-5 \mathrm{~h}$ and cooled) and quenched (heated to $750^{\circ} \mathrm{C}$ and chilled to room temperature) are identical (figure 1) as that observed for $\beta-\mathrm{CdV}_{2} \mathrm{O}_{6}$ and the strong $2 \theta$ reflection peak of $\alpha-\mathrm{CdV}_{2} \mathrm{O}_{6}$ corresponding to $d_{201}=3.52 \AA$ is absent (Brown 1972). However, XRD results indicate variations in the intensity of reflections corresponding to $d=4.40 \AA$ ( $20 \overline{1}$ plane) and $d=3 \cdot 10 \AA$ (201 plane) of $\mathrm{CdV}_{2} \mathrm{O}_{6}$. The DTA result of $\mathrm{CdV}_{2} \mathrm{O}_{6}$ (figure 2) showed phase transition at $185^{\circ} \mathrm{C}$, as was observed by Brown (1972); in contrast to the results of Bouloux and Galy (1969) who noticed the phase transition at $670^{\circ} \mathrm{C}$.

Bouloux and Galy (1969) and Brown (1972) have shown that the phase transition in $\mathrm{CdV}_{2} \mathrm{O}_{6}$ is reversible; however, our results (DTA and XRD) did not indicate any such possibility. Therefore, the structural transition $(\alpha \rightarrow \beta)$ is irreversible for $\mathrm{CdV}_{2} \mathrm{O}_{6}$. Angenault (1970) could prepare only $\beta-\mathrm{CdV}_{2} \mathrm{O}_{6}$ and did not report phase transition. The high temperature XRD powder patterns of the samples is desirable at this stage of investigation to confirm the reversibility of phase transformation process. The phase studies of $\mathrm{CdO}-\mathrm{V}_{2} \mathrm{O}_{5}$ system (Tammann and Kelsing 1925; Brown 1972) showed an eutectic $\left(\beta-\mathrm{CdV}_{2} \mathrm{O}_{6}\right.$-liquid phases) at $650 \pm 15^{\circ} \mathrm{C}$ in the phase diagram. Therefore, one can clearly understand that the endotherm at $670^{\circ} \mathrm{C}$ observed by Bouloux and Galy (1969) is not the phase transition temperature for $\mathrm{CdV}_{2} \mathrm{O}_{6}$.

Cadmium metavanadate $\left(\beta-\mathrm{CdV}_{2} \mathrm{O}_{6}\right)$ is isostructural with brannerite $\left(\mathrm{ThTi}_{2} \mathrm{O}_{6}\right)$ crystal structure (Wadsley and Ruh 1966) with monoclinic symmetry (space group 


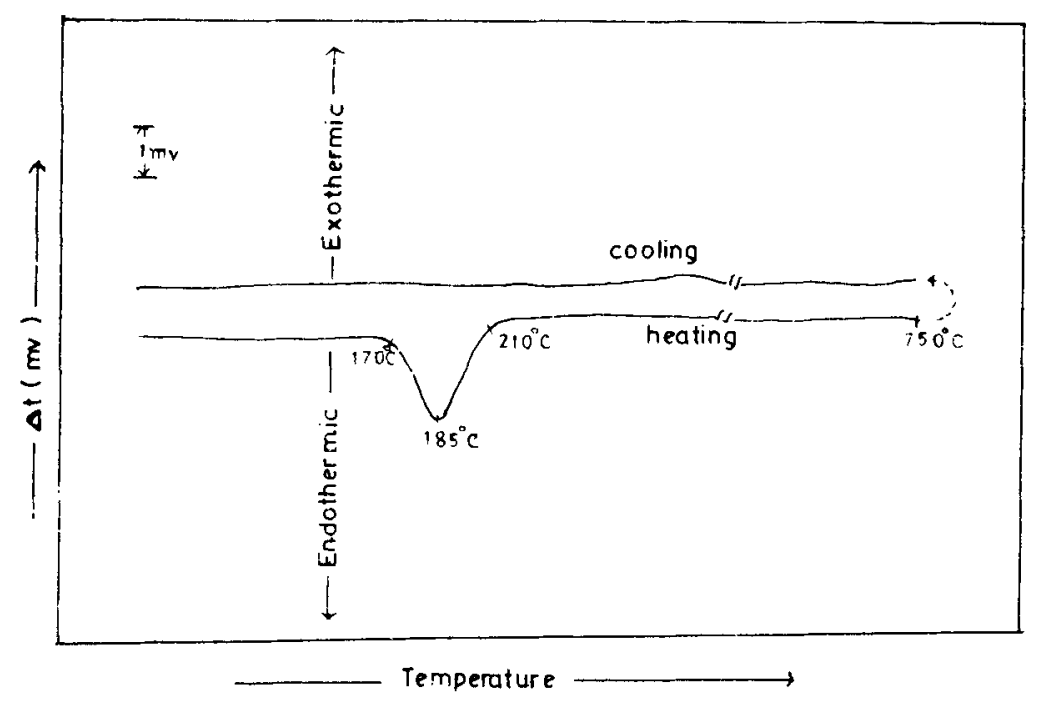

Figure 1. DTA of cadmium metavanadate.

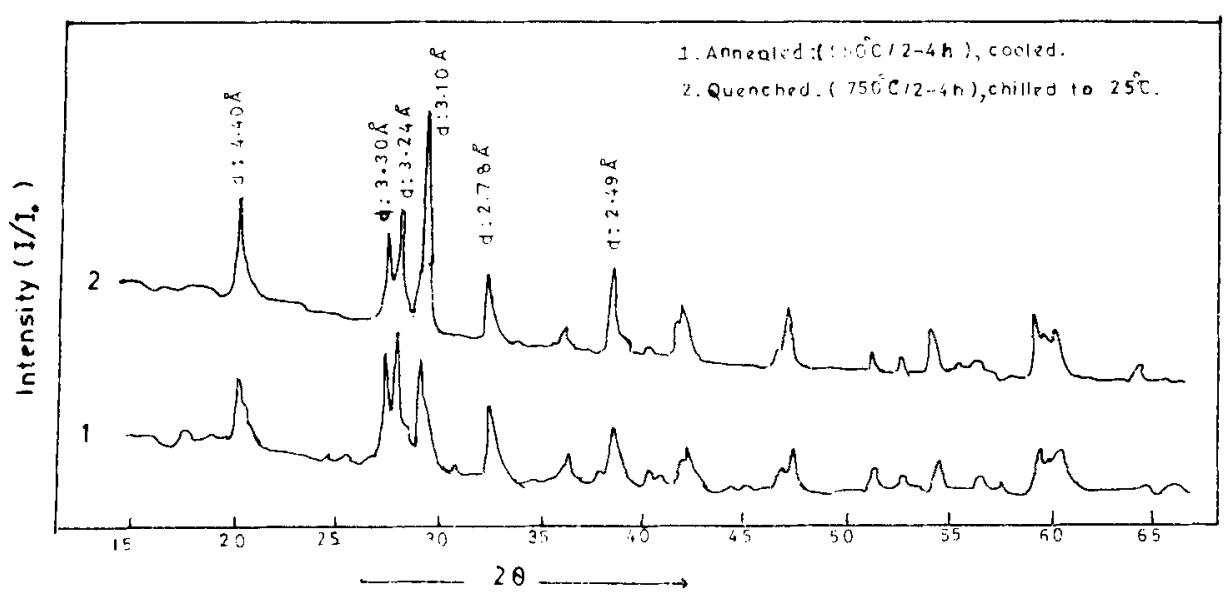

Figure 2. XRD powder patterns of 1. annealed and 2. quenched $\mathrm{CdV}_{2} \mathrm{O}_{6}$ samples.

$C 2 / m$ ). The crystal structure of $\beta-\mathrm{CdV}_{2} \mathrm{O}_{6}$ (moneclinic, $\mathrm{C} 2 / m$ ) is given in figure $3 \mathrm{~b}$ (Bouloux and Galy 1969), which is also isostructural with $\mathrm{MgV}_{2} \mathrm{O}_{6}$ (monoclinic $C 2 / \mathrm{m}$ ) ( $\mathrm{Ng}$ and Calvo 1972). This class of $\beta-\mathrm{CdV}_{2} \mathrm{O}_{6}$ crystal can be described as brannerite type crystal structure, composed of distorted $\mathrm{VO}_{h}$ octahedra which share opposite corners forming chains parallel to $\mathrm{b}$-axis. $\mathrm{VO}_{6}$ octahedra in adjacent chains share edges $\left(\mathrm{O}-\mathrm{O}_{3}\right.$ ) on one side of the chain. On the other side chains interleaf such that one $\mathrm{VO}_{6}$ octahedron shares two edges with two adjacent $\mathrm{VO}_{6}$ octahedra in a neighbouring chain (b-axis). The vanadium -oxygen bond distances in $\mathrm{VO}_{6}$ octahedra (figure $3 \mathrm{~b}$ ) of $\beta-\mathrm{CdV}_{2} \mathrm{O}_{6}$ crystal varies from 1.69 to $2.46 \AA . \mathrm{Cd}^{2+}$ ion lies in the octahedral interstices sharing oxygen atoms with 5 different vanadium ions. $\mathrm{CdO}_{6}$ octahedra form chains parallel to the b-axis by sharing edges with equivalent $\mathrm{CdO}_{6}$ groups (Bouloux and Galy 1969). 

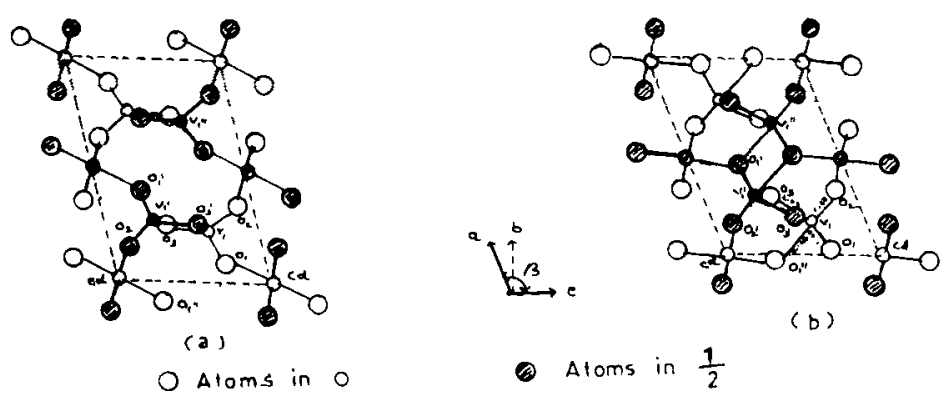

Figure 3. Projection of the structure of (a) $\alpha-\mathrm{CdV}_{2} \mathrm{O}_{6}$ and (b) $\beta-\mathrm{CdV}_{2} \mathrm{O}_{6}$ on the plane a-c.

The crystal structure of $\alpha-\mathrm{CdV}_{2} \mathrm{O}_{6}$ (monoclinic, $\mathrm{C} 2 / \mathrm{m}$ ) was discussed by Bouloux et al (1972) who reported that this crystal structure is isostructural with $\mathrm{CaV}_{2} \mathrm{O}_{6}$ (monoclinic, $C 2 / \mathrm{m}$ ). In the brannerite related crystal structure of this type, unlike $\beta-\mathrm{CdV}_{2} \mathrm{O}_{6}$, vanadium has five coordination (C.N-5) of oxygen atoms (trigonal bipyramidal $\mathrm{VO}_{5}$ group) in $\alpha-\mathrm{CdV}_{2} \mathrm{O}_{6}$ and the cadmium has octahedral (C.N-6) environment of oxygen atome $\left(\mathrm{CdO}_{6}\right.$ group). Both the $\mathrm{VO}_{5}$ and $\mathrm{CdO}_{6}$ groups of $\mathrm{CdV}_{2} \mathrm{O}_{6}$ form zig zag chains parallel to the b-axis (figure 3a). The vanadiumoxygen bond distances of $\mathrm{VO}_{5}$ group (trigonal bipyramidal) in $\alpha-\mathrm{CdV}_{2} \mathrm{O}_{6}$ varies from 1.71 to $1.88 \AA$. This type of crystal structure could arise in $\alpha-\mathrm{CdV}_{2} \mathrm{O}_{6}$ (figure 3a) due to loss of the sixth long vanadium-oxygen bond (V-O:3.67 $\AA$ ) between the vanadium of $\mathrm{VO}_{5}$ group and oxygen of the $\mathrm{CdO}_{6}$ group in the (201) plane of $\alpha-\mathrm{CdV}_{2} \mathrm{O}_{6}$ with the retention of identical symmetry (monoclinic, $C 2 / m$ ), as that observed for $\beta-\mathrm{CdV}_{2} \mathrm{O}_{6}$.

Since there is no change in the crystal symmetry (monoclinic, $C 2 / m$ ) of both $\alpha$ and $\beta$-phases of $\mathrm{CdV}_{2} \mathrm{O}_{6}$ during the transformation (Bouloux and Galy 1969; Bouloux et al 1972), the XRD powder patterns are expected to be nearly identical; however, a shift in the intensity and XRD $2 \theta$ reflections $\left(d_{h k l}\right)$ of high temperature phase could arise only if there is small translation or reduction in $d_{h k l}$ in any one of the $d_{h k l}$ planes or due to contraction of the unit cell parameters. A clear indication of the reduction in the interplanar spacings of $d_{201}$ planes of $\mathrm{CdV}_{2} \mathrm{O}_{6}$ crystal is evident from a shift of XRD $2 \theta$ reflection peak from $d_{201}=3.52 \AA$ to $d_{201}=3 \cdot 10 \AA$ (Bouloux and Galy 1969) for $\beta-\mathrm{CdV}_{2} \mathrm{O}_{6}$. Therefore, one can attribute the DTA peak at $185^{\circ} \mathrm{C}$ to structural transformation (identical crystal symmetry) from $\alpha-\mathrm{CdV}_{2} \mathrm{O}_{6}$ to $\beta-\mathrm{CdV}_{2} \mathrm{O}_{6}$ phase for the following reasons: the low temperature, $\alpha-\mathrm{CdV}_{2} \mathrm{O}_{6}$ phase (monoclinic, $\mathrm{C} 2 / \mathrm{m}$ ), crystallized in the brannerite related crystal structure (figure 3a). A small displacement of oxygen atoms of $\mathrm{VO}_{5}$ (trigonal bipyramid) group takes place in a-c plane of the crystal during the structural transformation of $\alpha-\mathrm{CdV}_{2} \mathrm{O}_{6}$, followed by a minor rotation of $\left(\sim 8^{\circ}\right) \mathrm{CdO}_{6}$ octahedra about b-axis and a consequent displacement of the (201) plane containing oxygen $\left(\mathrm{O}_{1}\right)$ to facilitate the sixth coordination of vanadium $\left(\mathrm{V}_{1}\right)$ to give $(\mathrm{V}-\mathrm{O}=2.46 \AA)$ a distorted $\mathrm{VO}_{6}$ octahedra (figure 3b). This mode of structural changes from $\alpha-\mathrm{CdV}_{2} \mathrm{O}_{6}$ to $\beta-\mathrm{CdV}_{2} \mathrm{O}_{6}$ (monoclinic, $\mathrm{C} 2 / \mathrm{m}$ ) is followed by a contraction of the unit cell parameters of $\alpha-\mathrm{CdV}_{2} \mathrm{O}_{6}$ (a volume decrease from $243 \AA^{3}$ to $216 \AA^{3}$ ) and also associated with a marked increase in the unit cell angle, $\beta\left(\sim 8^{\circ}\right)$, as was reported by Bouloux and Galy (1969). 
The results of the dc electrical conductivity $(\sigma)$ (figure 4) indicates that $\sigma$ follows a relationship of the form

$$
\sigma=\frac{\sigma_{0}}{T} \exp \left[-\Delta G^{*} / K T\right]
$$

with activation energy of $1.40 \mathrm{eV}$.

The seebeck coefficient $(\alpha, \mu \mathrm{v} /$ degree $)$ is described by

$$
\alpha=\frac{A}{e T}-\log \frac{V^{5+}}{V^{4+}},
$$

for $\mathrm{CdV}_{2} \mathrm{O}_{6}$ where all the terms have their usual significance. The term ' $A$ ' represents the K.E transported by the migrating electrons. The value of $A / e T$ is small for ionic solids. In (2), $\mathrm{V}^{5+}\left(d^{0}\right)$ is the density of sites available for localized electrons, and $\mathrm{V}^{4+}\left(d^{1}\right)$ is the density of localized electrons, the concentration of which is very small $(x)$ and is dependent on the extent of oxygen defect lattice of $\mathrm{CdV}_{2} \mathrm{O}_{6}$.

The cadmium metavanadate is an insulator in the pure and stoichiometric state. The electrical conductivity $(\sigma)$ data indicated that $\beta-\mathrm{CdV}_{2} \mathrm{O}_{6}$ is $n$-type semiconductor between $185^{\circ}$ and $750^{\circ} \mathrm{C}$, which is due to deviation from stoichiometry of oxygen lattice of $\mathrm{CdV}_{2} \mathrm{O}_{6}$. The phase of $\beta-\mathrm{CdV}_{2} \mathrm{O}_{6}$ is predominantly ionic and the electrons are localized. Therefore the only mode of electron transport is via the thermally activated jumps on equivalent vanadium sites (b-axis) of the $\mathrm{CdV}_{2} \mathrm{O}_{6}$ lattice.

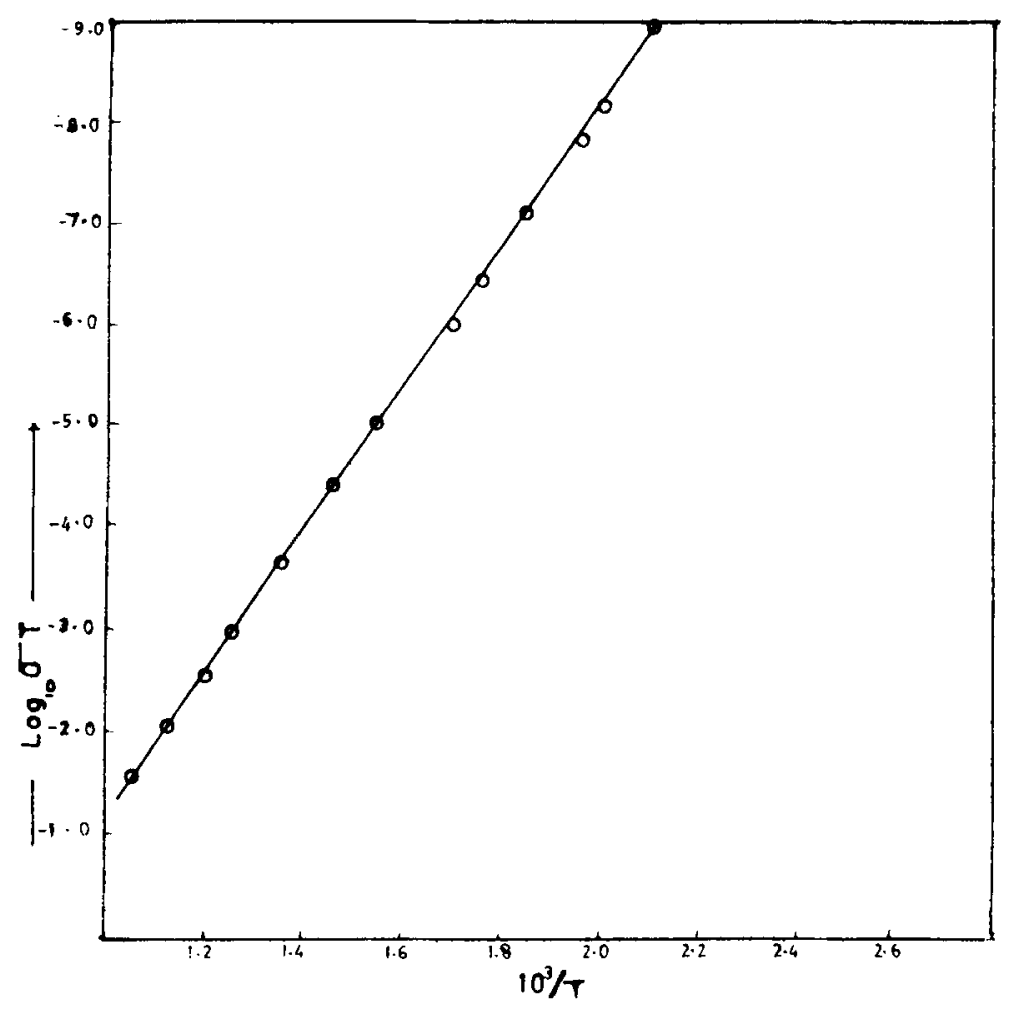

Figure 4. Plot of $\log _{10} \sigma T$ vs $10^{3} / T$. 
A nearly constant number of electrons (for very small value of $x$ ) are indicated for the seebeck coefficient $(\alpha, \mu \mathrm{v} /$ degree $)$ of $\beta-\mathrm{CdV}_{2} \mathrm{O}_{6}$ and is temperature independent. This behaviour could be attributed to vacant oxygen lattice model of $\mathrm{CdV}_{2} \mathrm{O}_{6}$. At the conditions of preparation of the sample, oxygen vacancies (defect structure) occur in $\mathrm{CdV}_{2} \mathrm{O}_{6}$ lattice leaving behind two electrons per half molecule oxygen resulting in an oxygen deficient lattice.

$$
\mathrm{CdV}_{2} \mathrm{O}_{6} \rightarrow \mathrm{CdV}_{2} \mathrm{O}_{6-x}+\frac{x}{2} \mathrm{O}_{2}+2 x e
$$

In other words, $\mathrm{CdV}_{2} \mathrm{O}_{6}$ can be represented as

$$
\mathrm{Cd}^{2+} \mathrm{V}_{2}^{5+} \mathrm{O}_{6} \rightarrow \mathrm{Cd}^{2+} \mathrm{V}_{2-2 x}^{5+} \mathrm{V}_{2 x}^{4+} \mathrm{O}_{6-x}
$$

Therefore, $n$-type semiconduction in $\beta-\mathrm{CdV}_{2} \mathrm{O}_{6}$ can be explained as follows: both $\mathrm{Cd}^{2+}\left(d^{10}\right)$ and $\mathrm{V}^{5+}\left(d^{0}\right)$ are in their highest oxidation states in cadmium metavanadate. The $\beta-\mathrm{CdV}_{2} \mathrm{O}_{6}$ has oxygen deficient lattice structure (4) due to deviation from oxygen stoichiometric composition of the lattice (3). The $2 x$ electrons released per $\frac{1}{2} \mathrm{O}_{2}$ molecule are trapped only on the $\mathrm{V}^{5+}\left(d^{0}\right)$ sites as localized electrons for conduction which results in the formation of $\mathrm{V}^{4+}\left(d^{1}\right)$ sites in the lattice of $\beta-\mathrm{CdV}_{2} \mathrm{O}_{6}$ (figure $3 \mathrm{~b}$ ) of the brannerite structure (Wadsley and Ruh 1966).

A negative and constant value $(-850 \mu \mathrm{v} /$ degree $)$ of seebeck coefficient $(\alpha)$ is observed for the sample and is temperature independent between 185 and $750^{\circ} \mathrm{C}$. Therefore, one can attribute that the only mode of transport in such a compound is via thermally activated jumps of localized electrons on vanadium sites of edge shared zig-zag sheets (b-axis) of $\mathrm{VO}_{6}$ octahedra of the brannerite related $\beta-\mathrm{CdV}_{2} \mathrm{O}_{6}$ structure (figure $3 \mathrm{~b}$ ). This $n$-type semiconduction ( $\mathrm{V}^{4+}$ : localized electrons in $\mathrm{V}^{5+}$ lattice) of $\mathrm{CdV}_{2} \mathrm{O}_{6}$ is reminiscent of $n$-type semiconduction which is well established for many metavanadates of the general formula $\mathrm{MV}_{2} \mathrm{O}_{6}$ (where $\mathrm{M}=\mathrm{Zn}^{2+}, \mathrm{Mg}^{2+}, \mathrm{Cu}^{2+}, \mathrm{Co}^{2+}, \mathrm{Ni}^{2+}$ etc) under normal and $\mathrm{PO}_{2}$ conditions (Palanna 1976). However, evidences for the oxygen stoichiometry could be ascertained only from detailed studies of $p_{0}-\Delta w$ (weight change) $-T$, and $p_{0}-\sigma-T$ of $\beta-\mathrm{CdV}_{2} \mathrm{O}_{6}$ sample, which is desirable to confirm the above results. The infrared spectra observed for a few vanadates (figure 5) revealed that they are related to stretching vibration modes of vanadium-oxygen bond (and their force constant) of the $\mathrm{VO}_{6}$ octahedra (or $\mathrm{VO}_{5}$, trigonal bipyramid) of the brannerite related (Wadsley and Ruh 1966) crystal structure. The $\beta-\mathrm{CdV}_{2} \mathrm{O}_{6}$ (monoclinic, $C 2 / m$ ) sample exhibited $\mathrm{V}-\mathrm{O}$ stretching vibration modes at $855 \mathrm{~cm}^{-1}$ which is similar to that observed at $860 \mathrm{~cm}^{-1}$ for isostructural $\mathrm{MgV}_{2} \mathrm{O}_{6}$ (monoclinic, $C 2 / \mathrm{m}$ ) with identical $\mathrm{V}^{5+}$ ion site symmetry. The observed infrared absorption band at $855 \mathrm{~cm}^{-1}$ is due to stretching vibration modes of various vanadium-oxygen bond distances (figure $3 \mathrm{~b}$ ) of distorted $\mathrm{VO}_{6}$ octahedra (b-axis) of $\beta-\mathrm{CdV}_{2} \mathrm{O}_{6}$. The $\alpha-\mathrm{CdV}_{2} \mathrm{O}_{6}$ phase has $\mathrm{V}-\mathrm{O}$ bond distances as given in figure $3 \mathrm{a}$ and has $\mathrm{VO}_{5}$ (trigonal bipyramidal) group along the b-axis in the crystal structure. The stretching vibration modes of $\mathrm{VO}_{5}$ groups should be similar to the one observed $\left(\sim 940 \mathrm{~cm}^{-1}\right)$ for the IR spectrum of the $\mathrm{VO}_{5}$ groups of the isostructural $\mathrm{CaV}_{2} \mathrm{O}_{6}$ (monoclinic, $\mathrm{C} 2 / \mathrm{m}$ ) (Fredrickson and Hausen 1963) as shown in figure 5, which is due to higher force constants of the $\mathrm{V}-\mathrm{O}$ bonds of $\mathrm{VO}_{5}$ group than the $\mathrm{VO}_{6}$ octahedra of $\beta-\mathrm{CdV}_{2} \mathrm{O}_{6}$; while the IR band characteristics of the isotypic crystal structure of less symmetric compound $\mathrm{MgV}_{2} \mathrm{O}_{6}$ (monoclinic, space group, $\mathrm{C} 2$ ) and $\mathrm{ZnV}_{2} \mathrm{O}_{6}$ (monoclinic, $\mathrm{C2}$ ) are observed at about $860-870 \mathrm{~cm}^{-1}$ (for $\mathrm{VO}_{5}$, tetragonal base pyramid). 


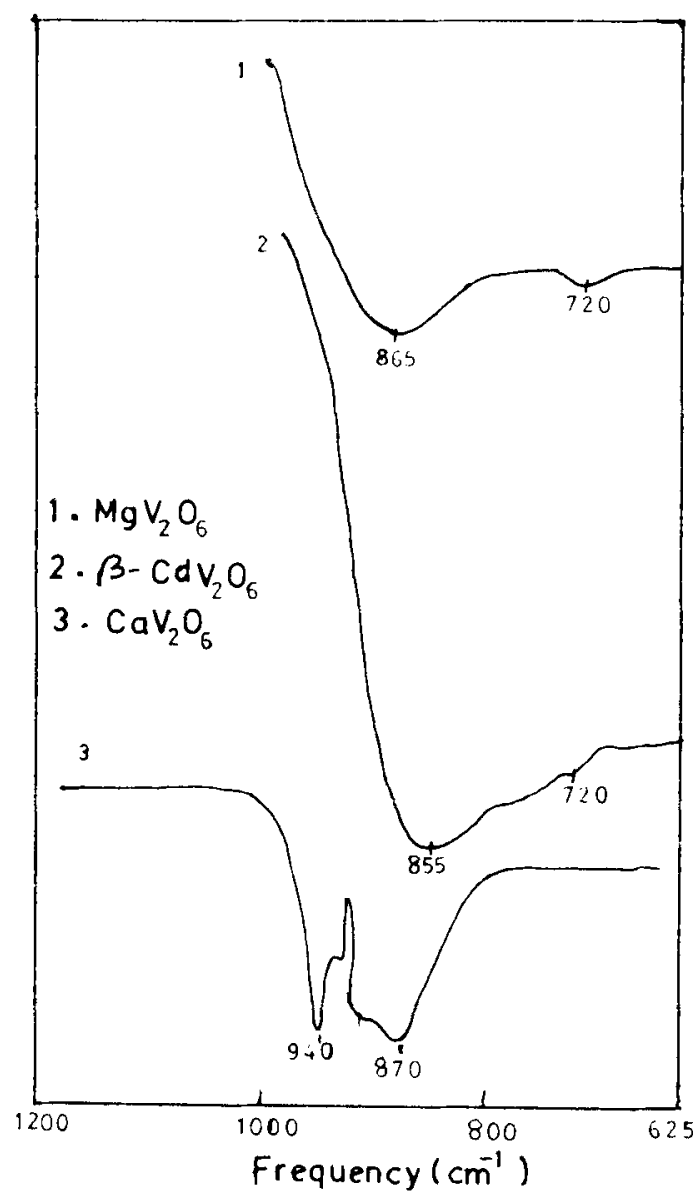

Figure 5. IR spectra of metavanadates.

\section{Acknowledgements}

The authors thank sincerely Rev. Fr. (Dr) L Mendonca, Principal, St. Philomena College, Puttur, for his stimulating encouragement and facilities. The authors thank UGC, New Delhi for a research grant. They also express their gratitude to Prof. H Sudhakar Nayak, Department of Metallurgy, KREC, Surathkal for providing IR and XRD of the samples.

\section{References}

Angenault J 1967 C. R. Acad. Sci. Ser. C 264435

Angenault J 1970 Renue de Chimie Mineral 17657

ASTM Card file No. $20-189$

Bouloux J C and Galy J 1969 Bull. Soc. Chem. Fr 3736

Bouloux J C. Perez G and Galy 1972 Bull. Soc. Fr. Mineral. Crystallogr. 95130

Brown J 1972 I. Am. Ceram. Six. 55500

Fredrickson L and Hausen D M 1963 Anul. Chem. 35818 
Lavaud D and Galy J 1972 Bull. Soc. Fr. Mineral. Crystallogr. 95134

$\mathrm{Ng} \mathrm{H} \mathrm{N}$ and Calvo C 1972 Canadian J. Chem. $\mathbf{5 0} 3619$

Palanna O G 1975 Studies on some mixed axide systems of vanadium, Ph. D Thesis, IIT, Bombay

Palanna O G 1979 Proc. Indian Acad. Sci. A88 19

Wadsley A D and Ruh R 1966 Acta Crystallogr. 21974

Tammann G and Kelsing H 1925 Z. Anorg. Chem. 114921 